\title{
Evaluation of timeliness of treatment initiation among smear positive pulmonary tu- berculosis patients in Brong Ahafo Region, Ghana, 2015
}

\author{
Charles L. Noora, Delia A. Bandoh, Robert D. Nuoh, Bismark Sarfo, Kofi M. Nyarko, and Ernest \\ Kenu
}

Ghana Med J 2020; 54(2) supplement: 73-82 DOI: http://dx.doi.org/10.4314/gmj.v54i2s.12 Ghana Field Epidemiology and Laboratory Training Programme, Department of Epidemiology and Disease
Control, University of Ghana School of Public Health, Accra, Ghana

Corresponding author: Ernest Kenu

E-mail: ernest_kenu@yahoo.com

Conflict of interest: None declared

\section{SUMMARY}

Background: We evaluated timeliness and factors influencing treatment initiation (TI) among smear positive pulmonary tuberculosis $(\mathrm{PTB}+)$ patients in Brong Ahafo Region (BAR), Ghana.

Design and Setting: We conducted a cross-sectional study in health facilities (HF) in six districts in BAR, from November 2014 to May 2015. Newly diagnosed smear positive PTB patients were selected randomly proportionate to size of facility cases. Timeliness of symptoms, diagnosis, TI and factors for delay were assessed using structured questionnaire. Patient delay was defined as presentation to a health care provider after 21 days of the onset of TBrelated symptoms and TI delay as therapy initiated after 30-days of onset of TB-related symptoms. We determined median patient timeliness, HF, and TI timeliness. We identified factors associated with TI delay using logistic regression.

Results: There were a total of 237 PTB+ patients; median patient timeliness of 30 days (IQR:14, 60). The median health facility timeliness was 8 days (IQR:4, 10); and the median TI timeliness was 36 days (IQR:25, 69). Majority $(58.7 \%)$ of patients delayed in seeking treatment. TI delay was associated with: unemployment [aOR=7.4, 95\% CI(1.9$28.8)]$, fear of losing job [aOR=3.4, 95\% CI(1.3-8.5)], traditional healer as first port of call [aOR=10.6, 95\% $\mathrm{CI}(13.0$ $66.8)]$, and initially being treated for $\mathrm{HIV}[\mathrm{aOR}=4.9,95 \% \mathrm{CI}(1.6-14.8)]$.

Conclusion: There were delays in treatment initiation and patient treatment seeking timeliness. One-third of patients would prefer traditional healers/self-treatment/drug store as an option. A concerted effort by stakeholders is needed to improve behaviour change communication on good health seeking behaviour for persons living with TB to reduce delays in seeking treatment.

Keywords: Pulmonary tuberculosis, timeliness, delay, Brong Ahafo Region, Ghana Funding: The study was funded by the authors

\section{INTRODUCTION}

The world's dream of eliminating TB by 2050 cannot be achieved without a radical change and a complete transformation in TB diagnosis, treatment and prevention. ${ }^{1}$ In the 21 st century, the world continues to count an unacceptable number of tuberculosis cases in all WHO regions every year. ${ }^{1}$ In $2015,8.6$ million incident cases were reported worldwide. More than $80 \%$ of new TB infections occurred in Asia and Africa. However, more than $30 \%$ of all TB incident cases are undiagnosed and untreated. ${ }^{1}$ Africa is burdened with about $25 \%$ of total global incident TB cases. ${ }^{1}$

The region is home to 15 of the 30 high TB burdened countries. ${ }^{1}$ The incidence of TB in Africa remains the highest worldwide, the 2013 rate of new infections was 280 per 100,000 populations with a total prevalence at
373 per 100,000 populations. The region also has the highest TB/HIV burden, a major risk factor for the progression of the disease. These compound the challenge of fighting the disease.

In Ghana, a national survey report revealed a prevalence rate of $264 / 100,000$ population. ${ }^{2}$ According to the WHO 2014 report, Ghana recorded 44,000 new cases in 2014 which translate into 165 newly infected people per 100,000 population. ${ }^{3}$ This makes Ghana one of the countries with the highest incident rates of TB. However, treatment success in Ghana has been reported to be $87 \%$, which is more than the WHO threshold. ${ }^{4}$ Case detection remains the challenge in Ghana's efforts at reducing the burden of TB. 
Case detection rate in Ghana currently stands at $33 / 100,000$ population. ${ }^{2}$ A recent study in Ghana revealed that about $50 \%$ of TB patients delay in seeking treatment with up an average of six months delay. Similarly, delay within the health care setting in Ghana average 8 weeks. ${ }^{4}$ A cross sectional study carried out among 73 new TB Patients, 15 years or older in Ghana, found more than 8 weeks delay among TB patients. ${ }^{5}$ Therefore, for Ghana to be able to achieve the target of eliminating TB by 2030 as envisioned in the sustainable development goals, efforts should be put in place to improve case detection.

The National Tuberculosis Control Programme (NTP) in Ghana is charged with the responsibility of providing leadership and health sector response to fight TB infection. The objective of the NTP is in line with the global target of achieving a $70 \%$ TB detection rate in communities and to reduce TB morbidity by $50 \%$ by $2030 .{ }^{1}$ In the Brong Ahafo Region (BAR) of Ghana, the rate of TB treatment delay is unknown, however the national TB control program over the years has implemented various control strategies including expanding and enhancing high quality directly observed treatment strategy (DOTS $)^{6}$ through patient support, improved diagnosis and treatment.

Despite these interventions, the burden of TB continues to increase. Several reasons have been attributed to this including increase incidence of HIV/AIDS co-infections and factors affecting health seeking behaviour of patients. ${ }^{7-10}$ Smear positive pulmonary tuberculosis $(\mathrm{PTB}+)$ remains the main contributor to total TB burden in Ghana. NTP is making efforts through the regions to provide equitable and high-quality care for the disease. However, in 2013, about $45 \%$ of total new TB cases were PTB.$+{ }^{11}$ Over $50 \%$ of TB cases occur among people between 15 and 49 years who mostly live in poor and crowded homes. ${ }^{1}$

In Ghana, TB detection is largely through screening of HIV/AIDS patients and passive case finding in local health facilities though in some areas active case finding is conducted periodically. Passive case findings are based on patient demographics, socioeconomic status, and their ability to access health facilities but also on the availability of trained and competent health staff and diagnostic equipment. This approach is partly dependent upon an individual with TB symptoms first recognising that he/she has symptoms of tuberculosis, then deciding to seek health care, and the ability of health care providers to accurately diagnose TB based on approved DOT strategy and standards for TB diagnosis and treatment. The guidelines for the clinical management of TB and HIV Co-infection in Ghana by the GHS ${ }^{12}$ stated that, diagnosis usually consisted of clinical screening by assessment of symptoms and signs, followed with sputum smear microscopy.

Other follow up diagnoses include chest x-rays and sputum cultures. These are carried out at all regional hospitals, teaching hospitals, and public health reference laboratories. The cornerstone of diagnosis of PTB in both PLWHIV and non-HIV individuals remains sputum smear microscopy. It is well known that most TB patients delay in treatment initiation especially among smear positive PTB patients. ${ }^{13,14}$ According to the WHO, TB patients who report to health care facilities more than 21 days from the onset of symptoms are considered to have delayed in seeking treatment. When patients report at a health facility with symptoms suggestive of TB, it is expected that diagnoses and initiation of treatment are done within two weeks. Periods beyond these time intervals are considered delayed.

Timely case detection and prompt treatment initiation are key because $\mathrm{PTB}+$ cases remain the main source of active infection in our communities. Delay in treatment worsens the prognosis and increases the period of infectivity ${ }^{15}$ in the region. More than $40 \%$ of all TB patients delay in seeking medical treatment. ${ }^{15-17}$ Access to health care, patient delay, and associated factors such as sex, educational level, family density and stigma contribute to delays in seeking healthcare. ${ }^{16,9}$

Health facility factors including patient waiting time, referral delays, diagnostics delays, ${ }^{17}$ health practitioners' ability to suspect TB at first visits and diagnosed TB early are thought to affect the timeliness of TB treatment initiation among $\mathrm{PTB}+$ patients visiting health facilities in BAR. Thus, the increasing number of new PTB + infections in the region is contrary to the improvement expected from DOTS expansion efforts in the region. Also, there are some motivational packages initiated by the $\mathrm{Na}$ tional TB control program (NTP) as measures to ensure TB patients report early to health facilities for care. However, we do not know the average timeliness of treatment in the region hence the need for this study. We evaluated timeliness and factors influencing treatment initiation (TI) among $\mathrm{PTB}+$ patients in Brong Ahafo Region (BAR), Ghana.

\section{METHODS}

\section{Study design}

We conducted a cross sectional study among smear positive PTB patients from six districts in the Brong Ahafo Region (BAR) of Ghana between November 2014 and May 2015 to access the factors associated with timeliness of treatment. 


\section{Study Area}

This study was conducted in Berekum, Sunyani, Techiman, Banda, Wenchi and Dormaa districts in Brong Ahafo Region (BAR), one of ten administrative regions of Ghana with an estimated population of 2.6 million. ${ }^{18}$ The region is further divided into 27 administrative districts with Sunyani as its capital. ${ }^{19}$ The region and indeed Ghana run a vertical public health service system where surveillance starts from the community level, district through the regional to the national level as well as feedback.

A large proportion of the inhabitants in BAR are settlers from the northern parts of the country. Majority of the people in BAR are engaged in farming and the region is seen as the food basket of Ghana. BAR has one of the largest markets in the West Africa located in Techiman with people moving to and from the region. TB control could therefore be a challenge. DOT coverage in BAR currently is over $80 \%$ using the national DOT strategy. Free diagnosis and treatments are offered as part of the NTP strategy together with enablers' package which involves costs of transportation and feeding.

\section{Study population}

The study population was smear positive pulmonary TB patients in selected district health facilities in the Brong Ahafo Region of Ghana.

\section{Sample size determination}

The sample size for the study was determined under the following assumptions: confidence interval of $95 \%$, a proportion of $44 \%$ for total delay more than 30 days among smear positive patients ${ }^{15}$, margin of error of $5 \%$, and an expected non-response rate of $10 \%$. Hence the calculated sample size was 379 . However, the size of the target population (number of smear positive PTB patients in BAR) in 2013 was small $(528)^{20}$, we considered a finite population correction for sample size. This made the final minimum sample size of the study 215 .

\section{Selection of participants}

Six districts which recorded the highest number of smear positive PTB cases in the region in 2013 were selected. Samples were proportionately allocated to the respective district facilities based on their estimated reported number of patients. Selection was done by reviewing TB registers at all district facilities using a checklist to obtain the list of all smear positive PTB cases recorded between 1st November 2014 and 31st May 2015. For each district, newly diagnosed and registered smear positive PTB patients were selected by systematic random sampling from the district's TB register. The first case registered during the period was selected as the first subject in each district.
Socio-demographic details of smear positive case patients were abstracted. Selected patients were interviewed at their respective DOT centers during routine visits. Selected $\mathrm{PTB}+$ patients who did not consent or could not be traced were replaced with the next available participant. Consenting PTB patients were interviewed about their knowledge on TB causes, symptoms, diagnosis, and treatment processes. The patient's TB treatment card/ sheet and TB registers were evaluated where appropriate to validate their responses.

\section{Operational definitions of timeliness}

Total Timeliness: average time interval between onset of symptoms and the actual start of anti-TB treatment

Patient timeliness: Time interval between onset of symptom and presentation to a healthcare provider

Service timeliness: Time interval between the date of patient presenting to a health care provider and the initiation of anti-TB treatment.

Diagnostic timeliness: Time interval between the onset of symptoms and the laboratory confirmation of tuberculosis.

Referral timeliness: Time interval between a patient's presentation to a healthcare provider, and the assessment for TB.

Smear positive $\mathrm{PTB}+$ patient: a patient with at least one sputum smear which is positive for acid fast bacilli; A patient with one or more initial sputum smear examinations (direct smear microscopy) for Acid Fast bacilli (AFB) positive; or one sputum examination AFB positive plus radiographic abnormality consistent with active pulmonary TB as determined by a Medical doctor, or other Health service provider.

\section{Inclusion criteria}

All smear positive PTB patients including TB/HIV coinfected individuals 18 years and older who attended any health facility of the selected districts and were newly diagnosed of PTB between 1st November, 2014 and 31st May 2015.

\section{Exclusion criteria}

Any smear positive PTB patient who has completed treatment, patients on follow up treatment, patients who have defaulted treatment and those known to have experienced treatment failure were excluded from this study.

\section{Data Collection Technique and Tools}

Data was extracted from the TB registers in the selected districts using a checklist. The checklist was designed to document the following information: date of initial visit, date diagnosed with TB, date treatment started, and patient folder number. Research assistants conducted face to face interviews with $\mathrm{PTB}+$ patients during their routine visits at the DOT centers using a structured questionnaire. 


\section{Data Quality Control}

We conducted training on data collection and entry. During data collection on the field, $10 \%$ of the completed questionnaires were selected by the supervisors at random and checked to identify errors and/or omissions and corrective actions made. The questionnaire was first piloted in Sunyani West District which is not part of the study sites but has similar characteristics to the selected districts.

\section{Data analysis}

Data was entered into Epi Info version 3.5.4 and validated, exported to STATA version 13 for analysis. Data was analysed descriptively and presented as frequencies and proportions. Continuous variables such as; age, number of days was summarised into mean, median and interquartile range.

Age was re-categorised into age groups at 10 years interval according to the WHO recommendation. ${ }^{21}$ PT, HFT and TIT (all continuous variables) were dichotomised and classified into delays (Yes/No). Patient delay was defined as more than three weeks ( $>21$ days) period ${ }^{22}$, Health facility delay as $>2$ weeks and treatment initiation delay was also dichotomised using the cut-off of more than 30 days for smear positives patients.

Pearson chi-square test was performed to determine significant differences between delays and other variables. Variables with $p$-value $<0.05$ at bivariate level were considered statistically significant. Binary logistic regression was done to determine factors associated with delays.

The significant variables and those proven plausible in literature to be risk factors for PTB including sex, age groups and patient residence were controlled for in a multiple logistic regression model to determine factors that were significant associated with delay. The results were presented as adjusted odds ratios (aORs) with corresponding 95\% confidence level.

\section{Ethical consideration}

Ethical clearance was obtained from Ghana Health Service Ethical Review Committee (GHS-ERC 12/10/14). Permission was obtained from the Brong Ahafo Regional Health Directorate and all District Health Management Teams involved in the study.

Written informed consent were signed by individual clients before responding to the questionnaire and confidentiality of responses was maintained. Data collected were only accessed by those directly involved in the research. All other information and data collected were stored under lock and key.

\section{RESULTS}

\section{Characteristics of study participants}

The questionnaire was successfully completed by $237 \mathrm{el}-$ igible smear-positive pulmonary tuberculosis (PTB) patients. Approximately 65\% (154/237) were males. Ages of participants ranged from 18 years to 82 years with a mean age of $(39.9 \pm 15.1)$ years (Table 1$)$.

Among the study participants, 52.1\% (112/215) reported to be living within a $10 \mathrm{~km}$ radius of a health service facility. For the patient's first port of call, 45.1\% (106/235) of patients went to public health facility, $17.5 \%(41 / 235)$ self-treated symptoms, $12.8 \%$ (30/235) visited a traditional healer, $12.8 \%(30 / 235)$ visited a private practitioner and $11.9 \%(28 / 235)$ went to a pharmacy shop.

The majority, $86.6 \%$ (187/216) of smear positive patients first visited a public health facility, $5.6 \%(12 / 216)$ in private and $7.8 \%(17 / 216)$ in others (herbalist, prayer camps).

\section{Timeliness for TB treatment initiation}

The median time between the onset of TB symptoms and patient reporting to a health facility (patient timeliness) was 30, IQR (14-60) days. Timeliness of diagnosis, treatment, and total timeliness was 4, IQR (3-7), 2, IQR (2-4) and 36, (25-69) days respectively. Median health service timeliness was 8, (IQR (5-15).

There were no statistical differences across sex in all forms of timeliness $(\mathrm{P}>0.05)$. Among patients who had knowledge that coughing for more than three weeks was a symptom of TB, median PT was 21 days IQR $(7-60)$ compared to those who did not know; median PT was 30 days IQR $(21-60)$ (Table 1).

\section{Proportion of smear positive PTB patients who de- layed in seeking health care}

Two patients were excluded in the subsequent analysis due to incomplete variable information. This gave a total of $235 \mathrm{PTB}+$ patients analysed. Of the total smear positive patients studied, $58.7 \%$ (138/237) of patients delayed in seeking treatment in a health facility; males $59.5 \%$ $(91 / 153)$ and females $57.3 \%$ (47/82). Specifically, over $90 \%(10 / 11)$ of patients who were initially treated for other conditions delayed in seeking care, $70.2 \%(33 / 47)$ delay was seen among those treating for HIV, $67.3 \%$ (21/31) for malaria and 44.3\% (43/97) among those who treated for RTIs. The highest proportion of patients who delayed in seeking treatment were those who visited a traditional healer as their first choice of treatment $83.3 \%$ $(25 / 30)$. Also, four homeless patients delayed in seeking care (Table 2). 
Table 1 Patient and health system timeliness of treatment initiation among smear positive Pulmonary TB patients, BAR, November 2014 - May 2015

Patient Timeliness (Days) $\quad$ Health facility Timeli- $\quad$ Total Timeliness (Days)

\begin{tabular}{|c|c|c|c|c|c|c|c|}
\hline \multirow[b]{2}{*}{ Variable } & \multirow[b]{2}{*}{ N (\%) } & \multicolumn{6}{|c|}{ ness (Days) } \\
\hline & & Median & IQR & Median & IQR & Median & IQR \\
\hline Overall & $237(100)$ & 30 & $(14-60)$ & 8 & $(4-10)$ & 36 & $(25-69)$ \\
\hline \multicolumn{8}{|l|}{ Sex } \\
\hline Female & $83(35.0)$ & 30 & $(14-60)$ & 5 & $(4-10)$ & 35 & $(25-69)$ \\
\hline Male & $154(65.0)$ & 30 & $(14-60)$ & 7 & $(5-14)$ & 37 & $(25-73)$ \\
\hline \multicolumn{8}{|l|}{ Age category (years) } \\
\hline$<34$ & $102(43.0)$ & 28 & $(7-30)$ & 5 & $(5-7)$ & 34 & $(15-47)$ \\
\hline$>34$ & $135(57.0)$ & 36 & $(21-60)$ & 6 & $(4-20)$ & 48 & $(25-73)$ \\
\hline \multicolumn{8}{|l|}{ Educational level } \\
\hline Tertiary & $31(13.1)$ & 21 & $(14-30)$ & 11 & $(5-12)$ & 37 & $(26-69)$ \\
\hline Primary/High school & $138(58.2)$ & 30 & $(14-60)$ & 7 & $(5-12)$ & 38 & $(26-76)$ \\
\hline No formal education & $68(28.7)$ & 30 & $(21-60)$ & 6 & $(4-10)$ & 31 & $(21-52)$ \\
\hline \multicolumn{8}{|l|}{ Residence } \\
\hline Urban & $61(25.7)$ & 30 & $(14-60)$ & 5 & $(4-11)$ & 34 & $(22-87)$ \\
\hline Semi urban & $65(27.4)$ & 30 & $(21-60)$ & 8 & $(5-17)$ & 41 & $(28-73)$ \\
\hline Rural & $107(45.2)$ & 30 & $(14-60)$ & 6 & $(4-10)$ & 37 & $(23-67)$ \\
\hline Homeless & $4(1.7)$ & 56 & $(18-105)$ & - & - & 85 & $(35-194)$ \\
\hline \multicolumn{8}{|l|}{ Distance to health facility } \\
\hline$\leq 10 \mathrm{~km}$ & $112(52.1)$ & 30 & $(14-60)$ & 7 & $(4-11)$ & 37 & $(24-69)$ \\
\hline$>10 \mathrm{~km}$ & $103(47.9)$ & 30 & $(14-37)$ & 5 & $(5-5)$ & 33 & $(33-53)$ \\
\hline \multicolumn{8}{|l|}{ Employment status } \\
\hline Employed & $45(19.0)$ & 21 & $(14-30)$ & 12 & $(11-15)$ & 30 & $(30-62)$ \\
\hline Self employed & $62(26.2)$ & 30 & $(21-60)$ & 7 & $(5-15)$ & 36 & $(26-67$ \\
\hline Unemployed & $130(54.8)$ & 30 & $(21-60)$ & 6 & $(4-10)$ & 39 & $(28-95)$ \\
\hline \multicolumn{8}{|c|}{$\begin{array}{l}\text { Heard of TB before diag- } \\
\text { nosis }\end{array}$} \\
\hline Yes & $165(76.0)$ & 30 & $(14-60)$ & 7 & $(4-12)$ & 36 & $(18-64)$ \\
\hline No & $52(24.0)$ & 30 & $(14-60)$ & 12 & $(7-17)$ & 36 & $(25-73)$ \\
\hline \multicolumn{8}{|l|}{ Treated initially for ${ }^{\#}$} \\
\hline RTI & $97(52.0)$ & 21 & $(14-37)$ & 5 & $(5-8)$ & 32 & $(22-62)$ \\
\hline Malaria & $31(17.0)$ & 30 & $(14-60)$ & 6 & $(4-15)$ & 36 & $(20-121$ \\
\hline HIV & $47(25.0)$ & 30 & $(21-60)$ & 7 & $(3-10)$ & 38 & $(31-69)$ \\
\hline Other & $11(6.0)$ & 50 & $(30-90)$ & 4 & $(4-4)$ & 96 & $(35-150)$ \\
\hline \multicolumn{8}{|l|}{$\begin{array}{l}\text { Patient first choice of } \\
\text { treatment }\end{array}$} \\
\hline Self-treated & $41(17.5)$ & 30 & $(14-80)$ & 5 & $(4-6)$ & 34 & $(30-63)$ \\
\hline Traditional healer & $30(12.8)$ & 40 & $(28-60)$ & 6 & $(5-8)$ & 51 & $(35-69)$ \\
\hline Public hospital/clinic & $106(45.1)$ & 25 & $(14-60)$ & 8 & $(5-17$ & 35 & $(22-76)$ \\
\hline Private practitioner & $30(12.8)$ & 30 & $(14-60)$ & 9 & $(5-12)$ & 44 & $(26-97)$ \\
\hline Pharmacist/vendor & $28(11.9)$ & 25 & $(14-60)$ & 9 & $(7-19)$ & 36 & $(20-64)$ \\
\hline \multicolumn{8}{|c|}{$\begin{array}{l}\text { Number of visits before di- } \\
\text { agnosis }\end{array}$} \\
\hline One & $34(16.8)$ & 30 & $(14-60)$ & 5 & $(3-13$ & 35 & $(23-92)$ \\
\hline Two & $73(36.1)$ & 30 & $(14-60)$ & 8 & $(5-11)$ & 35 & $(25-67)$ \\
\hline 3 or more & $95(47.1)$ & 30 & $(14-60)$ & 5 & $(4-7)$ & 36 & $(23-69)$ \\
\hline
\end{tabular}

${ }^{\#}$ missing variables

Different categories of timeliness for smear positive patients in BAR

The median patient time before reporting to a health facility was 30 days (IQR: 14-60). Diagnosis was 4 days (IQR: 3-7), and treatment initiation was 2 day (IQR 2-4) (Table 3)

Factors associated with TB treatment initiation delay Patient employment status, the effect on patient symptoms after initial treatment with non-TB drugs, fear of losing current job, patient first choice of treatment, initial diagnosis and patient knowledge of cough as a symptom of TB were found to be significantly associated with TB TIT delay (Table 3). Unemployed patients were about 7 times $(\mathrm{aOR}=7.4,95 \%$ CI $1.9-28.8)$ more likely to delay in treatment initiation compared to patients who were employed. The odds of TIT delay among patients whose first choice was to go to a traditional healer upon onset of symptoms was 10.6 times the odds of patients who chose to visit a public health facility $(95 \%$ CI $1.3-10.4)$. 
Table 2 Proportion of smear positive PTB patients with delay $>21$ days in seeking TB treatment

Patient delay $>21$ (Days)

\begin{tabular}{|c|c|c|c|c|}
\hline Characteristics & N (\%) & No n $(\%)$ & $\begin{array}{l}\text { Yes n } \\
(\%)\end{array}$ & $P$ value \\
\hline Sex & & & & 0.75 \\
\hline Male & $153(65.0)$ & $62(40.5)$ & $91(59.5)$ & \\
\hline Female & $82(35.0)$ & $35(42.7)$ & $47(57.3)$ & \\
\hline Age category (years) & & & & 0.47 \\
\hline$\leq 34$ & $101(43.0)$ & $39(38.6)$ & $62(61.2)$ & \\
\hline$>34$ & $134(57.0)$ & $58(43.3)$ & $76(56.7)$ & \\
\hline Educational level & & & & 0.26 \\
\hline No formal education & $67(28.5)$ & $26(38.8)$ & $41(61.2)$ & \\
\hline Primary/High school & $137(58.3)$ & $54(39.4)$ & $83(60.6)$ & \\
\hline Tertiary & $31(13.2)$ & $17(54.8)$ & 14(45.2) & \\
\hline Residence & & & & $0.75^{\circ}$ \\
\hline Urban & $61(26.0)$ & $27(44.3)$ & $34(55.7)$ & \\
\hline Semi urban & $64(27.2)$ & $27(43.8)$ & $36(56.2)$ & \\
\hline Rural & $106(45.1)$ & $40(37.7)$ & $66(62.3)$ & \\
\hline Homeless & $4(1.7)$ & $2(50.0)$ & $2(50.0)$ & \\
\hline Employment status & & & & 0.09 \\
\hline Self employed & $61(25.9)$ & $24(39.3)$ & $37(60.7)$ & \\
\hline Employed & $45(19.2)$ & $25(55.6)$ & $20(44.4)$ & \\
\hline Unemployed & $129(54.9)$ & $48(37.2)$ & $81(62.8)$ & \\
\hline \multicolumn{4}{|c|}{ Heard of TB before diagnosis } & 0.21 \\
\hline Yes & $165(76.0)$ & $70(42.4)$ & 95(57.6) & \\
\hline No & $52(24.0)$ & $17(32.7)$ & $35(67.3)$ & \\
\hline \multicolumn{4}{|c|}{ Knowledge of coughing $>3$ weeks as a TB symptom ${ }^{\#}$} & 0.11 \\
\hline Yes & $207(88.5)$ & $81(39.5)$ & $121(60.5)$ & \\
\hline No & $27(11.5)$ & $15(55.6)$ & $12(44.4)$ & \\
\hline \multicolumn{4}{|c|}{ After initial treatment with non-TB drugs, symptoms } & $0.01 *$ \\
\hline Improved & $46(22.0)$ & $18(39.1)$ & $28(60.9)$ & \\
\hline Worsened & $68(32.5)$ & $16(23.5)$ & $52(76.5)$ & \\
\hline Same & $95(45.5)$ & $44(46.3)$ & $51(53.7)$ & \\
\hline \multicolumn{3}{|c|}{ Patient first choice of treatment } & & $<0.01^{* 0}$ \\
\hline Self-treated & $41(17.4)$ & $17(41.5)$ & $24(58.5)$ & \\
\hline Traditional healer & $30(12.8)$ & $5(16.7)$ & $25(83.3)$ & \\
\hline $\begin{array}{l}\text { Public clinic/hospi- } \\
\text { tal/H/center }\end{array}$ & $106(45.1)$ & $53(50.0)$ & $53(50.0)$ & \\
\hline Private practitioner & $30(12.8)$ & $8(26.7)$ & $22(73.3)$ & \\
\hline Pharmacist/vendor & $28(11.9)$ & 14(50.0) & $14(50.0)$ & \\
\hline Overall & $235(100)$ & $97(41.3)$ & $138(58.7)$ & \\
\hline
\end{tabular}

*p-value refers to statistical comparison of proportions of patients with delay $>21$ days with independent variables, ${ }^{\circ}=$ Fisher's exact test, ${ }^{*}$ missing variables

Table 3 Different categories of total timeliness separated by sex of study participants

\begin{tabular}{|c|c|c|c|c|}
\hline Timeliness & $\begin{array}{l}\text { Total (both male } \\
\text { and female) }\end{array}$ & Male & Female & P-Value \\
\hline \multicolumn{5}{|l|}{$\begin{array}{l}\text { Patient timeli- } \\
\text { ness (days) }\end{array}$} \\
\hline Mean $( \pm$ SD $)$ & $51(88)$ & $54(91)$ & $46(82)$ & \\
\hline Median & 30 & 30 & 30 & \\
\hline IQR & $14-60$ & $14-60$ & $14-60$ & 0.509 \\
\hline Delayed, n (\%) & $138(58.7)$ & $91(59.5)$ & $47(55.3)$ & \\
\hline \multicolumn{5}{|l|}{$\begin{array}{l}\text { Diagnostic time- } \\
\text { liness (days) }\end{array}$} \\
\hline Mean $( \pm$ SD) & $14(32)$ & $15(36)$ & $12(24)$ & \\
\hline Median & 4 & 4 & 4 & \\
\hline IQR & $3-7$ & $2-10$ & $3-7$ & 0.668 \\
\hline Delayed, n (\%) & $98(41.4)$ & $66(42.9)$ & $32(38.6)$ & \\
\hline \multicolumn{5}{|l|}{$\begin{array}{l}\text { Treatment time- } \\
\text { liness (days) }\end{array}$} \\
\hline Mean $( \pm$ SD) & $9(49)$ & $10(59)$ & $7(22)$ & \\
\hline Median & 2 & 2 & 2 & \\
\hline IQR & $2-4$ & $1-4$ & $2-4$ & 0.556 \\
\hline Delayed, n (\%) & $154(44.1)$ & $70(45.5)$ & $84(54.5)$ & \\
\hline \multicolumn{5}{|l|}{$\begin{array}{l}\text { Health system } \\
\text { timeliness (days) }\end{array}$} \\
\hline Mean $( \pm$ SD $)$ & $23(62)$ & $25(69)$ & $20(44)$ & \\
\hline Median & 8 & 7 & 5 & \\
\hline IQR & $5-15$ & $5-14$ & $4-10$ & 0.843 \\
\hline Delayed, n (\%) & 153(64.6) & $99(64.3)$ & $54(65.1)$ & \\
\hline \multicolumn{5}{|l|}{$\begin{array}{l}\text { Total timeliness } \\
\text { (days) }\end{array}$} \\
\hline Mean $( \pm$ SD $)$ & $74(130)$ & $78(146)$ & $65(94)$ & \\
\hline Median & 36 & 37 & 35 & \\
\hline IQR & $25-69$ & $25-73$ & $25-69$ & 0.175 \\
\hline Delayed, n (\%) & $154(65.0)$ & $103(66.9)$ & $51(61.4)$ & \\
\hline
\end{tabular}

Table 4 Logistic regression analysis of factors influencing total patient delay (timeliness) in treatment initiation Delay (>30 days) $\quad$ Unadjusted P-value Adjusted P-value

\begin{tabular}{|c|c|c|c|c|c|c|}
\hline Variable & Yes $(\%)$ & No $(\%)$ & OR $(95 \% \mathrm{CI})$ & & OR $(95 \% \mathrm{CI})$ & \\
\hline $\operatorname{Sex}^{\wedge}$ & & & & 0.40 & & 0.33 \\
\hline Female & $51(61.4)$ & $32(38.6)$ & 1.0 & & 1.0 & \\
\hline Male & $103(66.9)$ & $51(33.1)$ & $1.3(0.7-2.2)$ & & $1.5(0.6-3.6)$ & \\
\hline Age category (years) $)^{\wedge}$ & & & & 0.45 & & 0.39 \\
\hline$\leq 34$ & $69(67.6)$ & $33(32.4)$ & 1.0 & & 1.0 & \\
\hline$>34$ & $85(63.0)$ & $50(37.0)$ & $08(0.4-1.4)$ & & $0.8(0.2-4.2)$ & \\
\hline Residence $^{\wedge}$ & & & & 0.08 & & 0.62 \\
\hline Urban & $38(62.3)$ & $23(37.7)$ & 1.0 & & 1.0 & \\
\hline Semi urban & $36(55.4)$ & $29(44.6)$ & $0.8(0.4-1.5)$ & & $0.1(0.1-0.4)^{*}$ & \\
\hline Rural & $76(71.0)$ & $31(29.0)$ & $1.5(0.8-2.9)$ & & $0.3(0.1-1.0)$ & \\
\hline Homeless & $4(100.0)$ & $0(0.0)$ & 1.0 & & - & - \\
\hline Employment status & & & & 0.02 & & 0.01 \\
\hline Employed & $22(48.9)$ & $23(51.1)$ & 1.0 & & 1.0 & \\
\hline Self employed & $39(62.9)$ & $23(37.1)$ & $1.8(0.8-3.9)$ & & $2.7(0.7-10.3)$ & \\
\hline Unemployed & $93(71.5)$ & $37(28.5)$ & $2.6(1.3-5.3)^{*}$ & & $7.4(1.9-28.8)^{*}$ & \\
\hline \multicolumn{2}{|c|}{$\begin{array}{l}\text { After treatment with non-TB drugs, symp- } \\
\text { toms }\end{array}$} & & & 0.09 & & 0.13 \\
\hline Same & $59(62.1)$ & $36.7(37.9)$ & 1.0 & & 1.0 & \\
\hline Improved & $33(71.7)$ & $13(28.3)$ & $1.5(0.7-3.3)$ & & $1.3(0.4-4.3)$ & \\
\hline
\end{tabular}




\begin{tabular}{|c|c|c|c|c|c|c|}
\hline & Delay $(>30$ & & Unadjusted & P-value & Adjusted & P-value \\
\hline Worsened & 53(79.9) & $15(22.1)$ & $2.2(1.1-4.4)^{*}$ & & $1.5(0.5-5.3)$ & \\
\hline losing current job & & & & 0.01 & & 0.01 \\
\hline No fears & $69(57.5)$ & $51(42.5)$ & 1.0 & & 1.0 & \\
\hline Fear & $71(74.0)$ & $25(26.0)$ & $2.1(1.2-3.8)^{*}$ & & $3.4(1.3-8.5)^{*}$ & \\
\hline $\begin{array}{l}\text { Patient first choice of } \\
\text { treatment }\end{array}$ & & & & 0.09 & & 0.21 \\
\hline $\begin{array}{l}\text { Public health facil- } \\
\text { ity }\end{array}$ & $61(57.5)$ & $45(42.5)$ & 1.0 & & 1.0 & \\
\hline Self-treated & $28(68.3)$ & 13(31.7) & $1.6(0.7-3.4)$ & & $1.4(0.5-4.7)$ & \\
\hline Traditional & $25(83.3)$ & $5(16.7)$ & $3.7(1.3-10.4)^{*}$ & & $10.6(1.3-66.8)^{*}$ & \\
\hline Private facility & $22(73.3)$ & $8(26.7)$ & $2.0(0.8-4.9)$ & & $1.2(0.3-4.1)$ & \\
\hline Pharmacy/vendor & $18(64.3)$ & $10(35.7)$ & $1.3(0.6-3.1)$ & & $3.0(0.6-10.9)$ & \\
\hline Treated initially for & & & & $<0.001$ & & $<0.01$ \\
\hline RTI & $50(51.6)$ & $47(48.4)$ & 1.0 & & 1.0 & \\
\hline Malaria & $22(71.0)$ & $9(29.0)$ & $2.3(0.9-5.5)$ & & $3.0(0.8-11.1)$ & \\
\hline HIV & $36(76.6)$ & $11(23.4)$ & $3.1(1.4-6.7)^{*}$ & & $4.9(1.6-14.8)^{*}$ & \\
\hline Other & $11(100.0)$ & $0(0.0)$ & - & & - & \\
\hline $\begin{array}{l}\text { Patient cough }>3 \\
\text { weeks }\end{array}$ & & & & $<0.01$ & & 0.91 \\
\hline No & $86(63.7)$ & $49(36.3)$ & 1.0 & & 1.0 & \\
\hline Yes & $67(67.6)$ & $32(32.3)$ & $2.6(1.4-4.7)^{*}$ & & $0.7(0.1-3.3)$ & \\
\hline
\end{tabular}

\section{DISCUSSION}

The study evaluated timeliness of treatment initiation and associated factors for delay among smear positive pulmonary tuberculosis patients in Brong Ahafo Region. More than half $(58.7 \%)$ of all smear positive pulmonary TB patients included in the study delayed in seeking treatment. Average duration of timeliness of treatment initiation ranged from three weeks among individuals who previously had heard of TB symptoms to three months among individuals who initially treated TB symptoms for other conditions. The median time of one month, taken by patients from the onset of symptoms until they sought treatment was found to be longer than the acceptable time interval ( 3 weeks) recommended by the World Health Organization. $^{23}$

Nonetheless, the median patient time (PT) found in this study was consistent with a previous study from southern Ethiopia where median time of treatment initiation was one month. ${ }^{9}$ This delay despite TB treatment in Ghana being free, poses a serious challenge to curtailing the burden of TB in the region. The principal reasons for delays in seeking treatment could be due to inadequate knowledge on TB, embarrassment individuals feel after being diagnosed with TB, and patient tendency to selfmedicate prior to seeking formal medical attention. ${ }^{24}$ Most patients reported that they had heard of TB and many were aware that it affected the lungs, however, they were not familiar with other symptoms. Many patients expressed confusion that their non-pulmonary symptoms, such as fevers or fatigue, were indicative of TB.
Participants tend to assume that their symptoms were not serious and could be treated with a basic drug from a pharmacy. In a study by Paz-Soldan et al, it was reported that, some patients preferred to consult an herbalist or use herbal remedies for treatment, before seeking formal medical care. In most cases, pharmacists or naturalists provide what they feel to be helpful, effective advice. ${ }^{24}$ The regional and district health directorates need to sensitise traditional healers, drug sellers/pharmacist and religious leaders to refer symptomatic individuals to public health facilities for tuberculosis test.

Generally, patients spend a shorter period of time, about just a week in health facilities once they report to a public health facility before initiation of treatment in this study. With the establishment of TB DOTS centers and chest clinics in most health facilities in the region, patient follow-ups are easier, especially when laboratory diagnosis are done within the facility.

Median health facility timeliness (HFT) was less than 10 days. This value agrees with an earlier finding from a systematic review of Indian literature by Sreeramareddy and colleagues which found the health facility timeliness was about 3 days. ${ }^{15}$ Another study involving 160 newly diagnosed PTB patients, median health service delay was found to be 9 days. ${ }^{8}$ On the contrary, median health system delays in Egypt 18, Iran Islamic republic 42 and $\mathrm{Pa}-$ kistan 87 were higher median days respectively. ${ }^{23}$ However lower ( $<4$ median days) HFT were reported from Iraq and Yemen. 
According to reports from $\mathrm{WHO},{ }^{23}$ Health system delay was the main contributor to the total delay in Pakistan, Islamic Republic of Iran and Egypt.

The total treatment initiation timeliness (TIT) in this study was shorter (36 days) than the median timelines found in other studies in some parts of Africa. In Malawi, the median days for treatment initiation was 80 days, ${ }^{25} 60$ median days were found in Gambia ${ }^{26}$ and 84 days in Botswana ${ }^{27}$. The findings were similar to an in-depth analysis of the health-seeking behaviour of patients and health system response in seven countries of the Eastern Mediterranean Region by the World Health Organization. ${ }^{23}$ In that review, 35 and 37.5 median days were found in Yemen and Iraq, respectively. The reasons for these variations are largely attributable to the methods employed in estimating the duration between times of onset of symptoms to the initiation of treatment, individual variations in the way they perceive diseases, the patient's understanding of what "onset of symptoms" means. The timeliness, therefore, is estimated considering a wide range of events and occurrences as well as the patient's perception of diseases. Although TB treatment in Ghana is free, a higher proportion close to $60 \%$ of smear positive PTB patients delayed in seeking treatment.

An earlier study conducted in Tigray, northern Ethiopia in public health institutions, ${ }^{28}$ showed that $81.2 \%$ of study participants experienced patient delay ( $>21$ days) in first consultation with a public health facility. Similarly among smear positive PTB patients 52\% delayed in seeking medical care in Bahir Dar City Administration, Northwest Ethiopia ${ }^{29}$ and more than $40 \%$ delay in Ghana ${ }^{5}$ However patient delay is still high in BAR, this is suggestive of limited impact on community interventions put in place to improve patient timeliness of reporting to public health facilities. However, other studies showed a lower proportion of delay among smear positive PTB patients. An Indian study looking at factors responsible for patient and treatment delays, reported $29 \%$ patient delays. ${ }^{30}$ It is generally believed that considerable proportion of TB patients in low and middle income countries do not have adequate knowledge on TB. ${ }^{31}$

Patient employment status proved to be significant predictors of delay in this study. Unemployed TB patients were about seven times more likely to delay in seeking and initiating TB treatment compared to those in formal employment. Fear and stigmatisation were also significant determinants of delay. Patients who were employed and were afraid of losing their jobs if diagnosed with TB had threefold increased odds of delay in treatment initiation. This same fear could be the reason why patients selfmedicated. Participants are probably afraid of job security and societal comments as revealed in a qualitative study in Lima, Peru by Paz-Soldan and colleagues. ${ }^{24}$
The Ministry of Health to engage with employers to ensure that employees diagnosed with TB at not at risk of losing their jobs, and that conditions of service for employees include care for TB.

Fear and/or embarrassment resulting from either being seen by other members of their community at the TB clinic or having an infectious disease and being discriminated against by peers, neighbours or health facility staff are some possible reasons for the delay. TB patients are usually worried of what people will say about them though everyone is at risk. ${ }^{24}$ The stigmatising attitudes and behaviours of the community members towards the disease and its sufferers may lead individuals with very obvious signs and symptoms of TB to attribute it to other non-stigmatising conditions or hide the diagnosis from others as well as default from treatment. ${ }^{32}$ Visiting a traditional healer upon first symptoms of disease and being treated initially for other infections were also significant risk factors for delay in TIT among smear positive patients which agrees with finding of another study among newly diagnosed sputum smear-positive pulmonary tuberculosis (TB) patients in Mumbai, India. ${ }^{33}$ Residence proved to be a significant risk factor for delay in the study where living in semi urban area was associated with a $90 \%$ reduced risk of delay in TIT for TB.

Contrary to this observation, findings from Iraq, Somalia, and Pakistan reported that semi urban residence significantly increased the odds of delay by $3,2.2$, and 2.5 folds, respectively. ${ }^{25}$ The differences in delays between the current study and previous studies elsewhere could be due to differences in the socio-demographics of the study populations. An overall assessment of the delay in initiating treatment after onset of symptoms, suggest that health system delay is relatively less compared to patient delay.

This finding is probably due to the effective decentralisation of TB treatments and implementation of the DOTS policy with effective referral and follows up of patients. However, what remains a major challenge to reducing new TB infections is that patients are staying longer at home with a high tendency to initially treat their symptoms by self-medicating with pharmaceutical drugs or natural homemade remedies.

A limitation of the study was recall bias since patients had to recall the time they actually started showing symptoms of the disease. To minimise this error, we used the local calendar to list the main national and religious eventss other timelines considered were farming seasons and cultural activities over a one year period in a chronological order to estimate the date of onset of symptoms. 


\section{CONCLUSION}

Timeliness of treatment initiation was good in the Brong Ahafo Region; an indication of a good health care system for TB diagnosis and management. There are delays in treatment initiation and patient treatment seeking timeliness. Public and private health facilities are first port of call for majority of patients. The factors that are significantly contributing to the treatment initiation delays are; unemployment, TB patient fear of losing current job, visiting a traditional healer upon first symptoms and also being on prior treatment for HIV.

\section{REFERENCES}

1. WHO. Global Tuberculosis Report 2013. World Health Organization Geneva. 2013.

2. GHS. Ghana Health Service 2014 annual report. GHS, Accra, 2015.

3. WHO. Ghana Tuberculosis profile 2016. WHO, Geneva 2017. Available at: https://extranet.who.int/sree/Reports?op=Re-

plet\&name $=/$ WHO_HQ_Reports/G2/PROD/EXT/TBCountryProfile\&ISO2=GH\&outtype=pdf. (Accessed: 23rd March 2016)

4. Lawn SD, Afful B, Acheampong JW. Pulmonary tuberculosis: diagnostic delay in Ghanaian adults. Int. J. Tuberc. Lung Dis. Off. J. Int. Union Tuberc. Lung Dis. 1996: 2, 635-640.

5. Osei E, Akweongo P, Binka F. Factors associated with DELAY in diagnosis among tuberculosis patients in Hohoe Municipality, Ghana. BMC Public Health 2015: 15.

6. WHO. WHO Global tuberculosis report 2015. WHO, Geneva, 2016.

7. Owusu-Dabo E. et al. Mycobacterium tuberculosis Drug Resistance, Ghana. Emerg. Infect. Dis. 2006: 12, 1170-1172.

8. Kansiime C, Kiwuwa S. M, Levi M, Asiimwe BB, Katamba A. Health service delay among pulmonary tuberculosis patients presenting to a National Referral Hospital, Kampala, Uganda: a Cross sectional study. Pan Afr. Med. J. 15, (2013).

9. Asefa A, Teshome W. Total delay in treatment among smear positive pulmonary tuberculosis patients in five primary health centers, Southern Ethiopia: A cross sectional study. PLoS ONE 2014:9.

10. Narasimhan P, Wood J, MacIntyre CR, Mathai D. Risk factors for tuberculosis. Pulm. Med. 2013; 2013:828939.

11. NTP. National Tuberculosis Control Programme Report. Ghana NTP, Accra, 2013.

12. GHS. Guidelines for the Clinical Management of TB and HIV Co-infection in Ghana. GHS, Accra. 2007.
13. Sabawoon W, Sato H, Kobayashi Y. Delay in the treatment of pulmonary tuberculosis: a report from Afghanistan. Environ. Health Prev. Med. 2012: 17, 53-61.

14. WHO. Global tuberculosis report 2007. World Health Organization, Geneva. 2008.

15. Sreeramareddy CT, Panduru KV, Menten J, Ende J, Van den. Time delays in diagnosis of pulmonary tuberculosis: a systematic review of literature. $B M C$ Infect. Dis. 2009:9, 91.

16. Tarimo GB. Delay in seeking care among tuberculosis patients attending tuberculosis clinics in Rungwe district, Tanzania. (Muhimbili University of Health and Allied Sciences, 2012).

17. Lawn SD, Afful B, Acheampong JW. Pulmonary tuberculosis: diagnostic delay in Ghanaian adults. Int. J. Tuberc. Lung Dis. 1998:2, 635-640.

18. GSS. 2010 Population and Housing census. Ghana Statistical Service, Accra. 2012.

19. GoG. Ghana Brong Ahafo Region. Government of Ghana 2014. Available at: http://www.ghana.gov.gh/index.php/aboutghana/regions/brong-ahafo.

20. RHD, BAR. Annual performance report, Ghana health service: Brong Ahafo region, 2012. GHS, Sunyani, 2013.

21. WHO. Global Tuberculosis Report 2014. World Health Organization, Geneva. 2015. doi:10.1016/j.icrp.2009.12.007

22. Alavi SM, Bakhtiyariniyia P, Albagi A. Factors associated with delay in diagnosis and treatment of pulmonary tuberculosis. Jundishapur J Microbiol. 2015 Mar; 8(3): e19238.

23. WHO. Diagnostic and treatment delay in tuberculosis. WHO Eastern Mediterranean Regional Office, Cairo, 2006.

24. Paz-Soldan VA, Alban RE, Dimos Jones C, Powell AR, Oberhelman RA. Patient reported delays in seeking treatment for tuberculosis among adult and pediatric TB patients and TB patients co-infected with HIV in Lima, Peru: a qualitative study. Infect. Dis. 2014: 2, 281 (2014).

25. Makwakwa L, Sheu, M, Chiang, C-Y, Lin, S-L, Chang, P. W. Patient and health system delays in the diagnosis and treatment of new and retreatment pulmonary tuberculosis cases in Malawi. BMC Infect. Dis. 2014: 14, 132.

26. Lienhardt $\mathrm{C}$ et al. Factors affecting time delay to treatment in a tuberculosis control programme in a sub-Saharan African country: the experience of The Gambia. Int. J. Tuberc. Lung Dis. 2001: 5, 233-239.

27. Steen TW, Mazonde GN. Pulmonary tuberculosis in Kweneng District, Botswana: delays in diagnosis in 212 smear-positive patients. Int. J. Tuberc. Lung Dis. 1998: 2, 627-634. 
28. Mesfin MM. et al. Delays and care seeking behavior among tuberculosis patients in Tigray of northern Ethiopia. Ethiop. J. Health Dev. 2005: 19, 7.

29. Gebeyehu E, Azage M, Abeje G. Factors Associated with Patient Delay in Tuberculosis Treatment in Bahir Dar City Administration, Northwest Ethiopia. BioMed Res. Int. 2014, e701429.

30. Tobgay K, Sarma P, Thankappan K. Predictors of treatment delays for tuberculosis in Sikkim. Natl. Med. J. India 2006: 19, 60-3.

31. Yimer S. a Bjune G. a, Holm-Hansen C. Time to first consultation, diagnosis and treatment of $\mathrm{TB}$ among patients attending a referral hospital in Northwest, Ethiopia. BMC Infect. Dis. 2014: 14, 19.

32. Dodor, E. A. \& Kelly, S. 'We are afraid of them': Attitudes and behaviours of community members towards tuberculosis in Ghana and implications for TB control efforts. Psychol. Health Med. 2009: 14, 170-179

33. Tamhane, A. et al. Pulmonary Tuberculosis in Mumbai, India: Factors Responsible for Patient and Treatment Delays. Int. J. Prev. Med. 2012: 3, 569580 (2012). 